\title{
Free-hand thoracic pedicle screws placed by neurosurgery residents: a CT analysis
}

\author{
Vincent Y. Wang - Cynthia T. Chin • \\ Daniel C. Lu • Justin S. Smith • Dean Chou
}

Received: 1 April 2009/Revised: 21 December 2009/Accepted: 15 January 2010/Published online: 5 February 2010

(C) The Author(s) 2010. This article is published with open access at Springerlink.com

\begin{abstract}
Free-hand thoracic pedicle screw placement is becoming more prevalent within neurosurgery residency training programs. This technique implements anatomic landmarks and tactile palpation without fluoroscopy or navigation to place thoracic pedicle screws. Because this technique is performed by surgeons in training, we wished to analyze the rate at which these screws were properly placed by residents by retrospectively reviewing the accuracy of resident-placed free-hand thoracic pedicle screws using computed tomography imaging. A total of 268 resident-placed thoracic pedicle screws was analyzed using axial computed tomography by an independent attending neuroradiologist. Eighty-five percent of the screws were completely within the pedicle and that $15 \%$ of the screws violated the pedicle cortex. The majority of the breaches were lateral breaches between 2 and $4 \mathrm{~mm}$ (46\%). There was no clinical evidence of neurovascular injury or injury to the esophagus. There were no re-operations for screw replacement. We concluded that under appropriate supervision, neurosurgery residents can safely place free-hand thoracic pedicle screws with an acceptable breach rate.
\end{abstract}

Keywords Computed tomography · Free-hand . Pedicle screw $\cdot$ Resident $\cdot$ Thoracic

V. Y. Wang · D. C. Lu · J. S. Smith · D. Chou $(\bowtie)$ Department of Neurological Surgery, University of California, 505 Parnassus Ave., Box 0112, San Francisco, CA 94143-0112, USA

e-mail: choud@neurosurg.ucsf.edu

\section{T. Chin}

Division of Neuroradiology, Department of Radiology, University of California, San Francisco, San Francisco, CA, USA

\section{Introduction}

Pedicle screws are frequently used to instrument the thoracic spine, and placing these screws in a free-hand fashion with tactile palpation has become more prevalent. When comparing the advantages of pedicle screws over hooks, pedicle screws provide better pull-out strength, threedimensional control of deformity correction, and do not routinely violate the spinal canal if placed properly $[1,2]$. The small pedicle diameter in the thoracic spine (especially in the mid-thoracic spine) has made cannulating the thoracic pedicle more challenging than cannulating the lumbar pedicle. Initial experience of pedicle screws in thoracic spine, even in the hands of experienced surgeons, was noted to have high incidences of pedicle breaches, with up to $41 \%$ of the screws penetrating the cortex [3]. Later experience with thoracic pedicle screws was more positive, with breach rates in the 10-20\% range [4, 5]. In most of these series, fluoroscopy was used to guide the insertion of the pedicle screw. More recently, image guidance has also been developed for the insertion of pedicle screws. Although image guidance has decreased the rate of breaches significantly, it historically has also increased the operative time [6]. Moreover, image guidance is not widely available.

The free-hand thoracic pedicle screw technique has been well-described by Kim et al. [7] and one inserts pedicle screws based on anatomical landmarks and the tactile feel of probing the pedicles. Kim et al. [8] report a low complication rate with this technique; however, it is associated with a steep learning curve. Moreover, their reported breach rate is based upon a combination of spine fellow-placed and attending-placed pedicle screws. To our knowledge, there is no report of neurosurgery resident-placed pedicle screw breach rate using the free-hand technique. 
Given that an important part of the free hand technique relies on tactile feedback, first-hand experience is essential for learning this technique. Because the pedicle cannulation, tapping, and screw placement are done bilaterally by the residents under direct supervision at our institution, we wished to retrospectively analyze the rate at which the screws are completely placed within the pedicles. We used computed tomography (CT) scans to retrospectively analyze insertion of thoracic pedicle screws by neurosurgery residents under the guidance of the senior spine surgeon.

\section{Materials and methods}

We retrospectively studied our series of patients who underwent thoracic spine pedicle screw placement from 2004 to 2008 by one attending spine surgeon and identified all cases that had a postoperative CT scan of the thoracic spine or of the chest. At our institution, routine postoperative CT scans are not obtained to evaluate pedicle screws, but CT scans are obtained for other reasons: planning for a second stage of surgery, baseline scan for following tumor resection, radiosurgery treatment planning, or evaluating chest pathology (pulmonary embolus or effusion). Because the attending surgeon has the residents to place thoracic pedicle screws bilaterally, both right and left pedicle screws were analyzed. Cases in which a physician assistant was involved or in which the attending surgeon placed one or both sides of the pedicle screws were excluded. We identified 36 patients with CT scans of the chest or thoracic spine and included 32 patients in our study. Three of the patients were excluded because a physician's assistant was involved in their cases, and one patient was excluded because he underwent thoracic pedicle screw placement in the lateral decubitus position (during a simultaneous anterior/posterior approach) rather than the standard prone position. Thirty-two patients were included in this study. In these cases, the residents placed the pedicle screws under the supervision of the attending spine surgeon.

\section{Surgical technique}

The technique of free-hand thoracic pedicle screw placement is well-described in the paper by Kim et al. [7, 8], but we will briefly mention our technique here. First, the thoracic spinal level is confirmed under X-ray. The size and angulation of the thoracic pedicle is based on previously documented, standard anatomic descriptions of thoracic pedicles [9]. We then used the well-documented anatomic entry points for free-hand thoracic pedicle screws as described by Kim et al. [7, 8] in 2004. A small pilot hole is drilled with an AM- 8 side cutting burr. A curved pedicle probe is first introduced with the tip pointing laterally until approximately $20 \mathrm{~mm}$. The probe is then completely removed, rotated until it is pointing medially, re-inserted to its depth of $20 \mathrm{~mm}$ down the previously made track, and subsequently medially until $30 \mathrm{~mm}(25 \mathrm{~mm}$ if at T1-T3 in a small patient). The sagittal trajectory of the probe is based upon the external anatomy of the posterior thoracic spine-the lamina and spinous processes. The mediallateral angulation of the probe is based upon the level of the thoracic spine and is well described by Panjabi [9] or based upon preoperative CT imaging (if available). The hole is then palpated with a ball-tipped probe. If no breach is palpated, this is subsequently dilated with a straight pedicle probe (4.2 or a $5.2 \mathrm{~mm}$ depending upon the level). The hole is then palpated again. The hole is then tapped $1 \mathrm{~mm}$ smaller than the proposed screw diameter. This is again palpated. The screw is inserted. One lateral plain radiograph or single fluoroscopic image is taken to confirm that the length of the very first screw is appropriate and that the level instrumented is correct. Further screw lengths are then based upon the length of the first screw and the subsequent levels of the thoracic spine. Fluoroscopy is not used during actual screw placement, but it is used to confirm good placement after the screws have been placed. If fluoroscopy is not used, a lateral radiograph is taken to confirm screw placement.

If the resident is unable to properly cannulate the pedicle, the attending surgeon (DC) attempts to cannulate it. If he cannulates it correctly, the tapping and the placement of the screw are then performed by the resident. If the attending surgeon is not able to safely cannulate the pedicle, that pedicle is skipped. Out of 284 pedicles, 16 pedicles were abandoned because of the inability to safely cannulate them. Motor-evoked potentials and somatosensory-evoked potentials were used during the case to monitor the neurophysiological condition of the spinal cord, but no stimulation of the screws is performed.

\section{Analysis of the pedicle screw insertion}

Dedicated CT scans of the thoracic spine or CT scans of the chest were obtained. Each CT scan was evaluated independently by an attending neuroradiologist (CTC). For chest CT scans, the images were magnified and coned to evaluate the screws within the pedicles. Pedicle screws were marked as "in" if they were deemed fully contained within the pedicle walls. Any cortical violation was recorded as a violation. Cortical violations were recorded as either medial, lateral or anterior. Violations were quantified in millimeters and graded at either: no violation, 1-2 mm violation, 2-4 $\mathrm{mm}$ violation, or greater than $4 \mathrm{~mm}$ violation. 


\section{Results}

We identified 32 patients who underwent placement of thoracic pedicle screws and who had a postoperative CT scan of either the chest or thoracic spine (Table 1). Of the patients, 19 were male and 13 were female. The mean age of the patients was 51 with a range of 14-80. Indications of surgery included tumor (16 patients), deformity (7 patients), infection (7 patients), degenerative spine disease (1 patient) and trauma (1 patient) (Figs. 1, 2, 3).

A total of 268 screws were placed into 32 patients. The levels at which the screws were placed are shown in Table 2. Of the 268 screws placed, $227(85 \%)$ were deemed to be completely within the pedicle. There were 41 screws that had cortical violations. There were $16(6 \%)$ medial cortex violations and $24(8.9 \%)$ lateral cortex violations. The majority (68\%) of these breaches were between 2 and $4 \mathrm{~mm}$ (Table 3). However, there were five breaches that were over $4 \mathrm{~mm}$, two of them being medial breaches. There were also two $(0.75 \%)$ anterior vertebral body violations with one screw protruding 1-2 $\mathrm{mm}$ beyond the anterior cortex and another protruding $2-4 \mathrm{~mm}$ beyond the cortex.

Of the 12 thoracic spinal levels, T5 had the most number of breaches with 3 medial breaches, 6 lateral breaches, and 1 anterior cortical violation (which also had a lateral breach by the same screw). The mid-thoracic spine (T5-T8) accounted for 19 of the 41 screws with cortex violations. However, there were no neurological, vascular, or visceral injuries from any of these screws.

Among the patients with deformity, 85 screws were placed and 25 screws had breaches (29\%). Half of the breaches were located in the mid-thoracic spine (13 breaches). The most frequent pattern of cortex violation was a lateral cortex violation between 2 and $4 \mathrm{~mm} \mathrm{(12}$ violations).

In terms of levels of training, six postgraduate year (PGY)-6 residents placed 111 of the 268 screws, five PGY3 residents placed 74 of the screws, and five PGY-2

Table 1 Patient demographics

\begin{tabular}{ll}
\hline Male & 19 \\
Female & 13 \\
Mean age & 51 \\
Age range & $14-80$ \\
Indications for surgery & \\
Tumor & 16 \\
Deformity & 7 \\
Infection & 7 \\
Degenerative & 1 \\
Trauma & 1 \\
\hline
\end{tabular}

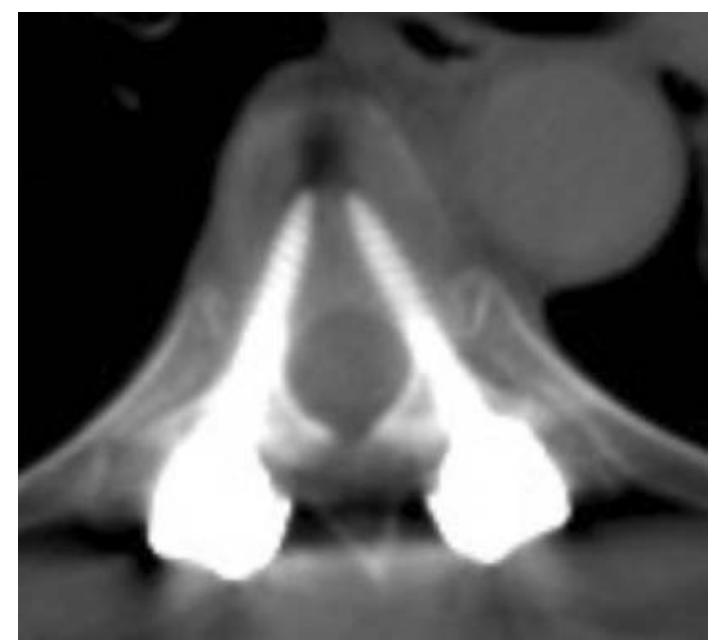

Fig. 1 Axial CT scan showing intrapedicular screw placement

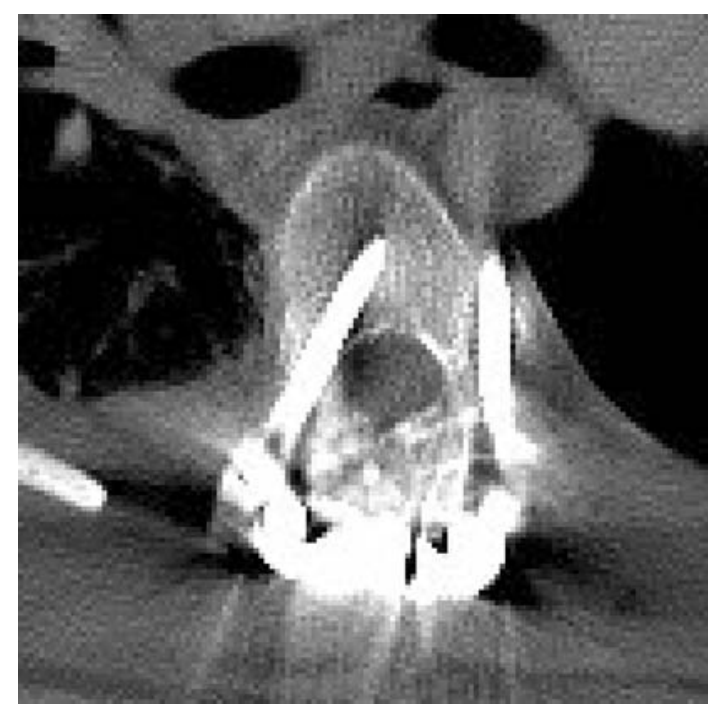

Fig. 2 Axial CT scan showing lateral cortical violation

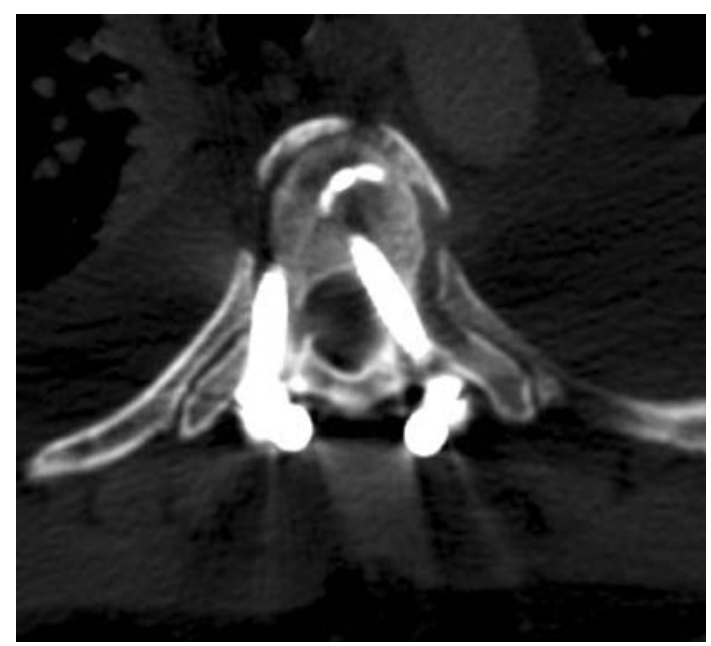

Fig. 3 Axial CT scan showing medial cortical violation 
Table 2 Pedicle screw placement by resident level

\begin{tabular}{lcccc}
\hline & PGY2 & PGY3 & PGY6 & Total \\
\hline T1 & 8 & 2 & 4 & 14 \\
T2 & 6 & 4 & 6 & 16 \\
T3 & 8 & 7 & 7 & 22 \\
T4 & 9 & 10 & 8 & 27 \\
T5 & 12 & 8 & 19 & 39 \\
T6 & 10 & 8 & 13 & 31 \\
T7 & 8 & 8 & 13 & 29 \\
T8 & 4 & 4 & 7 & 15 \\
T9 & 4 & 5 & 9 & 18 \\
T10 & 4 & 6 & 5 & 15 \\
T11 & 6 & 6 & 11 & 23 \\
T12 & 4 & 6 & 9 & 19 \\
Total & 83 & 74 & 111 & 268 \\
\hline
\end{tabular}

$P G Y$ postgraduate year in residency

Table 3 Pedicle screw breach distribution by degree of violation and level instrumented

\begin{tabular}{|c|c|c|c|c|c|c|c|}
\hline & \multicolumn{2}{|c|}{$<2 \mathrm{~mm}$} & \multicolumn{2}{|c|}{$2-4 \mathrm{~mm}$} & \multicolumn{2}{|c|}{$>4 \mathrm{~mm}$} & \multirow[t]{2}{*}{ Tota } \\
\hline & Med & Lat & Med & Lat & Med & Lat & \\
\hline $\mathrm{T} 1$ & 0 & 0 & 0 & 0 & 1 & 0 & 1 \\
\hline $\mathrm{T} 2$ & 0 & 0 & 1 & 1 & 0 & 0 & 2 \\
\hline $\mathrm{T} 3$ & 1 & 0 & 0 & 1 & 0 & 0 & 2 \\
\hline $\mathrm{T} 4^{\mathrm{a}}$ & 1 & 0 & 1 & 4 & 1 & 0 & 7 \\
\hline T5 & 2 & 0 & 3 & $6^{\mathrm{b}}$ & 0 & 1 & 12 \\
\hline T6 & 0 & 0 & 1 & 1 & 0 & 0 & 2 \\
\hline $\mathrm{T} 7$ & 1 & 0 & 0 & 2 & 0 & 0 & 3 \\
\hline $\mathrm{T} 8$ & 0 & 1 & 0 & 0 & 0 & 1 & 2 \\
\hline T9 & 0 & 0 & 0 & 2 & 0 & 0 & 2 \\
\hline $\mathrm{T} 10$ & 0 & 0 & 0 & 2 & 0 & 0 & 2 \\
\hline $\mathrm{T} 11$ & 0 & 0 & 0 & 0 & 0 & 1 & 1 \\
\hline $\mathrm{T} 12$ & 0 & 1 & 3 & 0 & 0 & 0 & 4 \\
\hline Total & 5 & 2 & 9 & 19 & 2 & 3 & $41^{\mathrm{a}}$ \\
\hline
\end{tabular}

a One of the T4 screws also had an anterior violation of 1-2 mm

${ }^{\mathrm{b}}$ One of the T5 screws also had a lateral violation of $2 \mathrm{~mm}$ and an anterior violation of 2-4 mm

residents placed 83 screws (see Tables 4, 5). The PGY-6 residents were associated with the highest rate of cortex violations, with $19 \%$ of the screws having violations (Table 5). Screws placed by the PGY-2 and PGY-3 residents had similar rate of cortical breaches, both occurred at 13\% (Table 5).

\section{Discussion}

Pedicle screw placement in the thoracic spine can be more challenging because of the smaller pedicles, potential deformity, the spinal cord's inability to tolerate significant deformation, and the difficulty of obtaining good intraoperative fluoroscopy at many levels $[3,10,11]$. Vaccaro et al. [3] had shown in a cadaver study that without the use of fluoroscopy, as many as $41 \%$ of thoracic pedicle screws violated the cortex and $23 \%$ of the screws had medial violation and entered the spinal canal. Nevertheless, pedicle screws have superior biomechanical properties as compared to hooks and have the ability to control the spine in the axial, coronal and sagittal planes [1, 2]. Moreover, unlike hooks, a properly inserted pedicle screw does not intentionally enter the spinal canal and can be just as strong in the presence of a laminectomy.

Fluoroscopy has been the most commonly used method to guide the insertion of pedicle screws into thoracic spine. In most surgical series, a 10-20\% rate of cortical violation is reported, although rates as high as $40 \%$ have been noted in some series $[4,5,12,13]$. Most of the violations were either contained within the rib head or protruded $<2 \mathrm{~mm}$ medially. The incidence of neurovascular injury or need for screw revision has been $<2 \%$ of patients $[4,5,12,14]$. In cases of scoliosis correction, fluoroscopy offers less anatomic information about the orientation and position of the pedicles due to the severe deformity, rendering it less useful [15].

Computer-assisted image guidance has also been used by spine surgeons. Many studies have shown that image guidance significantly decreases the cortical violation rate to less than 10\% [16-21]. The biggest drawback, however, is the increased operative time; some have calculated that image guidance increases the screw insertion time by as much 50\% at each level [6]. Moreover, the intervertebral anatomical relationship may change during surgery, increasing the potential risk of registration error with navigation [15]. Some authors have used a mixed strategy such as using image guidance for the upper and mid-thoracic spine-which tends to have smaller pedicles-and using the free-hand or fluoroscopic guidance techniques for the lower thoracic spine [17]. Recently, the free-hand technique has gained popularity. Kim et al. [7, 8] reported a series in which 8,000 screws had been placed by the freehand technique without neurovascular complications, and only $8 \%$ had significant breaches. The free-hand technique relies on anatomy and the tactile feedback for pedicle screw insertion. The anatomy can be learned, but the tactile feedback must be experienced first-hand. Thus, we feel it is important that the residents actually cannulate the pedicles themselves on both sides of the spine to maximize their experience. Moreover, detecting a breach of the pedicle wall by probing the pedicle is a skill with significant learning curve $[22,23]$. There are few substitutions for this experience other than personally feeling what a breach is like. 
Table 4 Degree of breaching by resident year

\begin{tabular}{|c|c|c|c|c|c|c|c|c|c|c|}
\hline & \multicolumn{3}{|l|}{ PGY2 } & \multicolumn{3}{|l|}{ PGY3 } & \multicolumn{3}{|l|}{ PGY6 } & \multirow[t]{2}{*}{ Tota } \\
\hline & $<2 \mathrm{~mm}$ & $2-4 \mathrm{~mm}$ & $>4 \mathrm{~mm}$ & $<2 \mathrm{~mm}$ & $2-4 \mathrm{~mm}$ & $>4 \mathrm{~mm}$ & $<2 \mathrm{~mm}$ & $2-4 \mathrm{~mm}$ & $>4 \mathrm{~mm}$ & \\
\hline $\mathrm{T} 1$ & 0 & 0 & 0 & 0 & 0 & 0 & 0 & 0 & 1 & 1 \\
\hline $\mathrm{T} 2$ & 0 & 0 & 0 & 0 & 0 & 0 & 0 & 2 & 0 & 2 \\
\hline $\mathrm{T} 3$ & 0 & 1 & 0 & 1 & 0 & 0 & 0 & 0 & 0 & 2 \\
\hline $\mathrm{T} 4$ & 0 & 2 & 0 & 1 & 1 & 0 & 1 & 2 & 1 & 8 \\
\hline T5 & 0 & 3 & 0 & 0 & 1 & 0 & 2 & 5 & 1 & 12 \\
\hline T6 & 0 & 1 & 0 & 0 & 0 & 0 & 0 & 1 & 0 & 2 \\
\hline $\mathrm{T} 7$ & 1 & 0 & 0 & 0 & 1 & 0 & 0 & 1 & 0 & 3 \\
\hline $\mathrm{T} 8$ & 1 & 0 & 0 & 0 & 0 & 1 & 0 & 0 & 0 & 2 \\
\hline T9 & 0 & 0 & 0 & 0 & 1 & 0 & 0 & 1 & 0 & 2 \\
\hline $\mathrm{T} 10$ & 0 & 1 & 0 & 0 & 0 & 0 & 0 & 1 & 0 & 2 \\
\hline $\mathrm{T} 11$ & 0 & 0 & 0 & 0 & 0 & 1 & 0 & 0 & 0 & 1 \\
\hline $\mathrm{T} 12$ & 1 & 0 & 0 & 0 & 1 & 0 & 0 & 2 & 0 & 4 \\
\hline Total & 3 & 8 & 0 & 2 & 5 & 2 & 3 & 15 & 3 & 41 \\
\hline
\end{tabular}

Table 5 Overall success rate of pedicle screw placement for each level

\begin{tabular}{lcccl}
\hline & PGY2 $(\%)$ & PGY3 $(\%)$ & PGY6 $(\%)$ & Overall $(\%)$ \\
\hline T1 & 100 & 100 & 75 & 93 \\
T2 & 100 & 100 & 67 & 88 \\
T3 & 87.5 & 86 & 100 & 91 \\
T4 & 78 & 80 & 50 & 70 \\
T5 & 75 & 88 & 58 & 69 \\
T6 & 90 & 100 & 92 & 94 \\
T7 & 88 & 88 & 92 & 90 \\
T8 & 75 & 75 & 100 & 87 \\
T9 & 100 & 80 & 89 & 89 \\
T10 & 75 & 100 & 80 & 87 \\
T11 & 100 & 83 & 100 & 96 \\
T12 & 75 & 83 & 78 & 79 \\
Overall & 87 & 87 & 81 & 85 \\
\hline
\end{tabular}

Our results have shown that under supervision, free-hand thoracic pedicle screws placed by neurosurgery residents have a $15 \%$ cortical violation rate, which is comparable to most surgical series. The majority of the violations ranged between 2 and $4 \mathrm{~mm}$. It has been shown that medial cortical violations of $<4 \mathrm{~mm}$ are unlikely to cause any neurological complications [7, 24, 25].

It is interesting that the PGY-6 residents had a $19 \%$ cortical breach rate, slightly higher than the $13 \%$ breaching rate of the PGY 2 and 3 residents. Many of the breaches originate from two patients, who account for 10 out of 21 breaches for the PGY-6 residents. One possible explanation is that the junior residents most likely had more strict supervision for placement of screws whereas the chief residents were given more independence (though still supervised) during placement of the screws. We had more lateral cortical breaches than medial breaches. The most likely explanation is the tendency to err laterally instead of medially. No vascular or pleural injuries were observed in these cortical violations.

This study is based upon postoperative thoracic spine CT scans and chest CT scans because CT scans have been shown to be more sensitive than radiographs in detecting cortical breaches [24]. We do not routinely obtain postoperative CT scans on every patient undergoing thoracic fusion because of cost and added radiation exposure, but we do perform CT scans if they are clinically indicated. Indications for $\mathrm{CT}$ in this patient cohort included: planning for further surgery, evaluation of bony resection, baseline to follow tumor recurrence or progression, radiosurgery treatment planning, or evaluation of possible chest pathology (e.g. pulmonary embolism, pleural effusion, etc.). One could argue that this created a selection bias: how does one know whether patients with "well-placed" screws seen on X-ray were selected for CT scanning and patients with "poorly placed" screws were excluded? This would be the case if we had selectively chosen to obtain CT scans in patients to evaluate pedicle screw placement; however, the indication to obtain a CT scan was not related to the placement of pedicle screws. That is to say, CT scans were not obtained because we wished to evaluate "wellplaced" or "poorly placed" pedicle screws; rather, they were obtained for clinical reasons without regards to intraoperative placement of the screws. Thus, because the CT scans were not obtained for evaluation of pedicle screw placement per se, we felt that this essentially became a reasonable random sampling of thoracic pedicle screw cases in this time period. 
Complex techniques in neurosurgery such as aneurysm clipping or thoracic screw placement require significant training and experience before the surgeon can master the technique. Several studies have analyzed the outcome of aneurysm clipping by neurosurgeons in training and noted no significant difference in outcome as compared to staff neurosurgeon-performed cases [26, 27]. However, it is important to ensure that quality care is nonetheless delivered, despite the role of training. For spinal instrumentation techniques, the anatomical relationship of bony landmarks can be learned by practicing on saw-bone models. Practicing on cadavers is another way to gain additional experience. However, neither saw-bones nor cadavers can replace the actual experience, especially the tactile feedback experience. Moreover, availability of cadavers is often limited. Therefore, our program does not have routine saw-bone or cadaver training sessions for residents. From our experience, training takes place best in the operating room. The typical training route consists of observation of the technique first, followed by execution of the technique under strict supervision. Thus, it is important to study the outcome of surgery in an advanced technique such as free-hand thoracic screw placement performed by trainees.

\section{Conclusion}

An analysis by CT scan shows that under proper guidance and supervision, neurosurgery residents in various years of training can safely place free-hand thoracic pedicle screws with a cannulation rate comparable to that of other published series.

Conflict of interest statement None of the authors has any financial interest in conjunction of production of this manuscript.

Open Access This article is distributed under the terms of the Creative Commons Attribution Noncommercial License which permits any noncommercial use, distribution, and reproduction in any medium, provided the original author(s) and source are credited.

\section{References}

1. Hackenberg L, Link T, Liljenqvist U (2002) Axial and tangential fixation strength of pedicle screws versus hooks in the thoracic spine in relation to bone mineral density. Spine 27:937-942

2. Liljenqvist U, Hackenberg L, Link T, Halm H (2001) Pullout strength of pedicle screws versus pedicle and laminar hooks in the thoracic spine. Acta Orthop Belg 67:157-163

3. Vaccaro AR, Rizzolo SJ, Allardyce TJ et al (1995) Placement of pedicle screws in the thoracic spine. Part I: morphometric analysis of the thoracic vertebrae. J Bone Joint Surg Am 77:11931199
4. Carbone JJ, Tortolani PJ, Quartararo LG (2003) Fluoroscopically assisted pedicle screw fixation for thoracic and thoracolumbar injuries: technique and short-term complications. Spine 28:91-97

5. Guzey FK, Emel E, Seyithanoglu MH et al (2006) Accuracy of pedicle screw placement for upper and middle thoracic pathologies without coronal plane spinal deformity using conventional methods. J Spinal Disord Tech 19:436-441

6. Laine T, Lund T, Ylikoski M et al (2000) Accuracy of pedicle screw insertion with and without computer assistance: a randomised controlled clinical study in 100 consecutive patients. Eur Spine J 9:235-240

7. Kim YJ, Lenke LG, Bridwell KH et al (2004) Free hand pedicle screw placement in the thoracic spine: is it safe? Spine 29:333342 (discussion 342)

8. Kim YJ, Lenke LG (2005) Thoracic pedicle screw placement: free-hand technique. Neurol India 53:512-519

9. Panjabi MM, Takata K, Goel V et al (1991) Thoracic human vertebrae. Quantitative three-dimensional anatomy. Spine 16:888-901

10. Datir SP, Mitra SR (2004) Morphometric study of the thoracic vertebral pedicle in an Indian population. Spine 29:1174-1181

11. McLain RF, Ferrara L, Kabins M (2002) Pedicle morphometry in the upper thoracic spine: limits to safe screw placement in older patients. Spine 27:2467-2471

12. Belmont PJ Jr, Klemme WR, Dhawan A, Polly DW Jr (2001) In vivo accuracy of thoracic pedicle screws. Spine 26:2340-2346

13. Fisher CG, Sahajpal V, Keynan O et al (2006) Accuracy and safety of pedicle screw fixation in thoracic spine trauma. J Neurosurg Spine 5:520-526

14. Bransford R, Bellabarba C, Thompson JH et al (2006) The safety of fluoroscopically-assisted thoracic pedicle screw instrumentation for spine trauma. J Trauma 60:1047-1052

15. Rajasekaran S, Vidyadhara S, Ramesh P, Shetty AP (2007) Randomized clinical study to compare the accuracy of navigated and non-navigated thoracic pedicle screws in deformity correction surgeries. Spine 32:E56-E64

16. Amiot LP, Lang K, Putzier M et al (2000) Comparative results between conventional and computer-assisted pedicle screw installation in the thoracic, lumbar, and sacral spine. Spine 25:606-614

17. Heary RF, Bono CM, Black M (2004) Thoracic pedicle screws: postoperative computerized tomography scanning assessment. J Neurosurg 100:325-331

18. Kamimura M, Ebara S, Itoh H et al (1999) Accurate pedicle screw insertion under the control of a computer-assisted image guiding system: laboratory test and clinical study. J Orthop Sci 4:197-206

19. Kim KD, Johnson JP, Babbitz JD (2001) Image-guided thoracic pedicle screw placement: a technical study in cadavers and preliminary clinical experience. Neurosurg Focus 10:E2

20. Merloz P, Tonetti J, Pittet L et al (1998) Pedicle screw placement using image guided techniques. Clin Orthop Relat Res 354:39-48

21. Youkilis AS, Quint DJ, McGillicuddy JE, Papadopoulos SM (2001) Stereotactic navigation for placement of pedicle screws in the thoracic spine. Neurosurgery 48:771-778 (discussion 778779)

22. Bergeson RK, Schwend RM, DeLucia T et al (2008) How accurately do novice surgeons place thoracic pedicle screws with the free hand technique? Spine (Phila Pa 1976) 33:501-507

23. Lehman RA, Potter BK, Kuklo TR et al (2004) Probing for thoracic pedicle screw tract violation(s): is it valid? J Spinal Disord Tech 17:277-283

24. Di Silvestre M, Parisini P, Lolli F, Bakaloudis G (2007) Complications of thoracic pedicle screws in scoliosis treatment. Spine 32:1655-1661 
25. Gertzbein SD, Robbins SE (1990) Accuracy of pedicular screw placement in vivo. Spine 15:11-14

26. Cunningham EJ, Debar S, Bell BA (2003) Association between surgeon seniority and outcome in intracranial aneurysm surgery. Br J Neurosurg 17:124-128 discussion 129
27. Woodrow SI, Bernstein M, Wallace MC (2005) Safety of intracranial aneurysm surgery performed in a postgraduate training program: implications for training. J Neurosurg 102:616-621 